\title{
Self Renewal of Spermatogonial Stem Cells: the Most Promising Multipotent Cells - A Review
}

\author{
J. Tokas ${ }^{1}$, C. S. Mukhopadhyay ${ }^{2} *$ and Archana Verma ${ }^{3}$ \\ 1. Department of Biochemistry, COBS \& H, CCS-Haryana Agricultural University, Hisar \\ 2. Department of Animal Biotechnology, GADVASU, Ludhiana, Punjab, India. \\ 3. Dairy Cattle Breeding Division, N.D.R.I., Karnal, Haryana \\ * Corresponding author. Tel.: +91-161-2414023, E-mail : csmscience@gmail.com \\ Published online at www.veterinaryworld.org on 25-03-2011
}

\begin{abstract}
Germ cells are endowed with unique properties like the ability to undergo meiosis and differentiate into gametes in order to perpetuate the genetic material. Spermatogonial stem cells (SSC) are considered as the best suited undifferentiated germ cells and are being consistently studied to reveal the basic physiology, genomics and transcriptomics of those cells. SSC provide an excellent model system to understand the differentiation, development and functioning of gonads and further use of these cells in transplantation-cell based therapies. In the present article, basic aspects of spermatogonial multiplication, regulation of stem cell renewal and differentiation would be discussed. Keyw ords: Spermatogonial stem cells, spermatogenesis, testis, self-renewal.
\end{abstract}

\section{Introduction}

In the current scenario, stem cells have egressed as one of the most fascinating areas of biological science. Stem cells are subject of increasing interest because of their biological properties and potential medical importance. Unfortunately, it has been difficult to penetrate much into the field, in part because of ambiguity about what exactly constitutes a stem cell. Stem cells, defined functionally as the precursor cells that give rise to other cell types, are also called as "progenitor cells". Stem cells have two characteristics that distinguish them from other cell types: firstly, they are uncommitted cells capable of self renewal for many generations through cell division.

The second being that under certain physiological and experimental conditions, they can be induced to become cells with specialized functions (Jaenisch and Young, 2008) such as the myocardial cells, insulin-producing cells of the pancreas, epithelial cells, neurons, macrophages, fat producing adipose cells etc. Stem cells are characterized according to the tissue from which they are derived. Stem cells may be embryonic stem cells or adult stem cells. Embryonic stem cells are derived from the inner cell mass (ICM) of preimplantation embryos (Evans and Kaufmann, 1981) embryonic germ cells and fetal germ cells (Matsui et al., 1992). Adult stem cells (those obtained from the adult tissues) have its primary role to maintain and repair the tissues in which they are found in a living organism. These cells have more restricted options to select a differentiation program from a few possible pathways only. Adult and embryonic stem cells differ in the number and type of differentiated cell types they can form. Embryonic stem cells can form all cell types of body (including germ cells) because they are totipotent (Rosant, 2008). Adult stem cells are generally limited to differentiating into different cell types of their tissue of origin only. "Although difficult to extract, since they are taken from the patient's own body, adult stem cells are superior to both umbilical cord and embryonic stem cells. There is always an exact DNA match so the body's immune system never rejects them. And as we might expect, results have been both profound and promising" (http://www.allabout popularissues.org/ pros-and-cons-of-stem-cell-research.htm).

Amongst the adult stem cells the best defined one is the spermatogenic system which depends on a small population of spermatogonial stem cells (SSC). SSC can renew them and produce daughter cells that are destined to differentiate into spermatozoa(Ogawa, 2008); hence they are the hub in the process to procreate the male germplasm. Spermatogenic stem cells experience around 10 successive mitotic divisions to yield primary spermatocytes (Tegelenbosch and de Rooij, 1993) which thereafter undergoes meiosis to beget approximately 2048 to 4096 spermatids (Russell et al., 1990). Hence, the regulation of the germ cell numbers is accomplished in the spermatogonial 


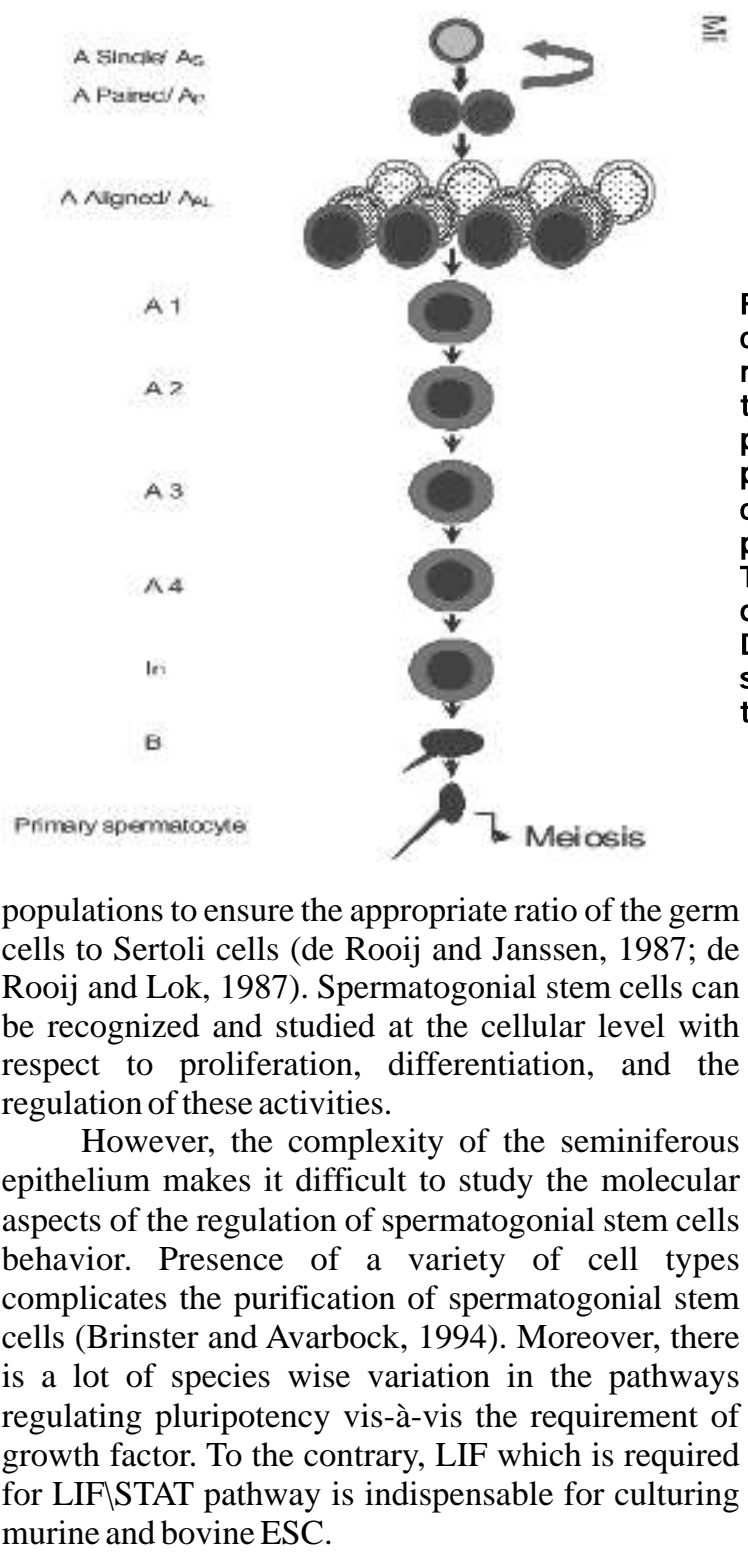

\section{Origin of spermatogonial stem cells}

Spermatogonial stem cells originate from the primordial germ cells (PGC), the progenitor cells for both the male and female germ line, which in turn derive from the epiblast cells (Lawson and Pederson, 1992). By 7 days post coitum in the mouse embryo, about 100 alkaline phosphatase positive PGCs can be detected in the extra embryonal mesoderm posterior to the definitive primitive streak (Ginsburg et al., 1990). Later in development, the PGCs migrate from the base of the allantois, along the hindgut to finally reach the
Figure-1. The phases of germ cell development. Stem cells give rise to spermatogonia that undergo several mitotic divisions over the next 10 days. More than half of the spermatogonia undergo apoptosis during the latter part of the mitotic phase. During much of the meiotic phase, the spermatocytes are in the $G_{2}$ phase of the cell cycle. After the two meiotic divisions at the end of this phase, germ cells enter the post-meiotic phase. Transcription occurs throughout the germ cell development until the midpoint of the post-meiotic phase. During the latter half of this phase, proteins are synthesized from transcripts that have been stored since the early part of the post-meiotic phase.

genital ridges. The $\mathrm{PGCs}$ proliferate during migration by day 13 of fetal life in the mouse, when these cells have enriched the genital ridges; their numbers increase to about 10,000 in each gonad (Tam and Snow, 1981). Once derived in the genital ridges, the PGC become enclosed by the differentiating Sertoli cells and the seminiferous cords are formed. The germ cells present within the seminiferous cords differ morphologically from PGC and are called gonocytes (Ogawa, 2008, Hersmusa et al., 2008). In rats and mice, the gonocytes are arrested in the $G_{0} / G_{1}$ phase of the cell cycle following a brief proliferation (Franchi and Mandl, 1964; Huckins and Clermont, 1968; Vergouwen et al. 1991). Slowly after birth, the gonocytes resume proliferation to give rise to $\mathrm{A}_{0}$ spermatogonia. This event marks the start of spermatogenesis. The male germ cell development occurs in successive mitotic, meiotic and post-meiotic phases with the germ cells moving from the periphery to the lumen of the seminiferous tubules. The mitotic phase occurs in the basal compartment, while the meiotic and postmeiotic phases occur in the luminal compartment. This takes about 35 days in the mouse, with the mitotic, meiotic and post-meiotic phases lasting for approximately 11,10 and 14 days, respectively (Clermont and Trott, 1969). The process begins every 8.7-8.9 days; however, the duration of these phases varies slightly between mouse species. It includes processes unique to germ cells, including meiotic 
genetic recombination, haploid gene expression, formation of acrosome and flagellum and the remodeling and condensation of chromatin, all of which must occur at the correct time to produce the male gamete (Abel et al., 2008). The highly ordered process of spermatogenesis, in turn, requires a precise and well coordinated programme that regulates the constantly changing patterns of gene expression.

\section{Cytological bases of spermatogonial multiplication and differentiation}

In the testis of adult mammalian species, spermatogonial stem cells maintain their numbers by self-renewal and give rise to differentiating germ cells. The spermatogonial stem cell system of the rhesus monkey is well studied (Clermont and Leblond, 1959; de Rooij et al., 1986; de Rooij et al., 2002; van Alphen and de Rooij, 1986; Marshall et al., 1995; Ramaswamy et al., 2000). In these macaques as well as in men, two morphologically distinguishable types of spermatogonia exist, the $\mathrm{A}_{\text {dark }}$ and the $\mathrm{A}_{\text {pale }}$ spermatogonia (Clermont, 1996a, b). Although both are commonly referred to as spermatogonial stem cells, their biological functions are very different. The $\mathrm{A}_{\text {pale }}$ cells show typical characteristics of a progenitor and proliferate at defined periods during each cycle of the seminiferous epithelium to produce both $\mathrm{A}_{\text {pale }}$ and there after $B$ spermatogonia . The $\mathrm{A}_{\text {dark }}$ cells also show high proliferative activity during pre-pubertal testicular development when the pool of both types of A spermatogonia is expanding (Simorangkir et al., 2000). Therefore, the $A_{\text {dark }}$ spermatogonium has been recognized as the 'true' testicular stem cell i.e. the regenerative reserve (Amann, 2008) while the $A_{\text {pale }}$ is considered as the male germ-line progenitor i.e. the functional reserve. The combination of a true stem cell with low mitotic activity and a progenitor producing high numbers of differentiating daughter cells seems to be the ideal system in the male germ line of primates, where both the maintenance of genomic integrity and output of millions of motile sperms are equally important to insure perpetuation of the genome to the next generation (Ramaswamy et al., 2000).

Spermatogonial multiplication and stem cell renewal can be best studied in whole mounts of seminiferous tubules, since this is the best technique to preserve the topographical arrangement of the cells (Clermont and Bustos-Obregon, 1968). The process of stem cell multiplication and renewal has been studied in different mammalian species. The spermatogonial stem cells (SSC) are accordingly termed as A-single
$\left(\mathrm{A}_{\mathrm{s}}\right)$, A-paired $\left(\mathrm{A}_{\mathrm{pr}}\right)$, A-aligned $\left(\mathrm{A}_{\mathrm{al}}\right), \mathrm{A}_{2}, \mathrm{~A} 3, \mathrm{~A}_{4}$, intermediate $\left(\mathrm{I}_{\mathrm{n}}\right)$ and $\mathrm{B}$-spermatogonia, depending on their stages of cycle (Fig 1). In non-primate mammals $\mathrm{A}_{\mathrm{s}}$ (A-single) spermatogonia are those stem cells that upon mitosis can divide into two new A-paired stem cells (Lok et al., 1982; de Rooij and Grootegoed, 1998). $A_{p r}$ spermatogonia which produce daughter cells that remain connected by an intercellular bridge further develop along spermatogenic line to divide into chains of $4 \mathrm{~A}_{\mathrm{al}}$ (A-aligned) spermatogonia.

The chains of $A_{a l}$ spermatogonia can divide further into chains of 8,16 and rarely 32 cells. Spermatogenesis is a cyclic process that in mice can be divided into 12 stages (I-XII). In stage VIII, the $A_{s}, A_{p r}$ and a few $\mathrm{A}_{\text {al }}$ spermatogonia are present. From stage $\mathrm{X}$ onwards, these cells start to proliferate in such a way that the number of $\mathrm{A}_{\mathrm{s}}$ and $\mathrm{A}_{\mathrm{pr}}$ spermatogonia remain relatively constant and more and more $\mathrm{A}_{\mathrm{al}}$ spermatogonia are formed. At about stages II-III (stage XII is followed by stage I), proliferation stops and the cells become arrested in $\mathrm{G}_{1}-\mathrm{G}_{0}$ phase. Subsequently, in stages VII-VIII, nearly all $\mathrm{A}_{\mathrm{al}}$ spermatogonia formed during the period of active proliferation differentiate into $\mathrm{A}_{1}$ spermatogonia, without division.

The $A_{1}$ spermatogonia enter S-phase and in stage IX divide into $A_{2}$ spermatogonia. There are 5 subsequent divisions into $A_{3}, A_{4}$, intermediate $\left(I_{n}\right)$ and B-spermatogonia and primary spermatocytes, respectively. In total, there are 9-11 mitotic divisions during spermatogonial development (van Alphen and de Rooij, 1986). Two differentiation steps take place in the developmental path of spermatogonia; namely, from the $A_{s}$ spermatogonia to the $A_{p r}$ spermatogonia and the second one is from $A_{\text {al }}$ to $A_{1}$ spermatogonia which brings about a marked change in cell behavior. These differentiation steps go through a series of 6 divisions to give rise to $A_{2}, A_{3}, A_{4}$, Intermediate (I) and $B$ and finally a primary spermatocyte (de Rooij, 2001; de Rooij et al., 1999). To investigate these steps, in vitro experiments using isolated germ cells have been performed (Ogawa, 2008). However, only a limited number of cells can be isolated as germ cells have a limited viability in culture and it is difficult to distinguish spermatogonial stem cells from more differentiated spermatogonia in vitro, due to the lack of specific stem cell markers. The establishment of stem cell line would overcome these problems (van Pelt et al., 2002).

Paucity of research reports on the transcriptomics of the proliferating spermatocytes has stood as an impediment towards developing a deeper insight 
about the proteomics of the spermatogenesis. Some events during spermatogenesis indicate the genetic control of the spermatogonial stem cell proliferation, differentiation and stem cell renewal. For instance, the spermatogonial stem cell renewal is highly preferred to $A_{P R}$ formation at the time of dearth of spermatocytes, similarly, the proliferation of $\mathrm{A}_{\mathrm{S}}, \mathrm{A}_{\mathrm{PR}}$ and $\mathrm{A}_{\mathrm{AL}}$ depends on the proportion of the $\mathrm{A}_{4}$ to $\mathrm{B}$ type cells towards the lumen (de Rooij, 2001). The spermatogonial stem cell research has yet to walk a long way before it could find its placement as a reliable tool for medical application in a multidimensional way. Recent findings have stated that the transgenic loss of function and over expression models reveal that the fate of undifferentiated spermatogonial cells depend on the dosage of the Sertoli cells produced glial cell linederived neurotrophic factor (GDNF) (Meng et al., 2000).

\section{Regulation of self-renewal and differen- tiation of spermatogonial stem cells}

The stem cell niche is a specialized microenvironment provided by supporting cells, which promotes self-renewal and retention of stem cells in their undifferentiated state. The Sertoli cell is recognized as one of those unique support cells, as it provides extrinsic signals for establishment and coordination of the complicated steps associated with spermatogenesis. As early as in 1865 , this tree like cell was identified as "sustentacular" or the mother cell, because it formed an intimate physical relationship with germ cells (Yasuzumi et al., 1960). In normal seminiferous epithelium, the ratio between selfrenewal and differentiation of spermatogonial stem cells should be about one (de Rooij, 2001). More selfrenewal than differentiation would reduce the seminiferous epithelium to only stem cells and a tumor might form (de Rooij, 1998). If incessant differentiation continues, the stem cells would deplete themselves leading to seminiferous tubules with only the supporting Sertoli cells.

The complexity of the seminiferous epithelium makes it difficult to study the spermatogonial multiplication and stem cells renewal at the molecular level. Prior to 1990's, there was a desperate need for suitable biochemical, intracellular and surface marker to identify the stem cells from the aggrandized spurious cell types in a culture. Discovery of c-kit receptors as spermatogonial stem cell markers has opened new avenue in stem cell research (Shinohara et al. 1999; Albanesi et al. 1996). C-kit receptor ligand system plays an important role in spermatogonial proliferation and differentiation. C-kit is involved in the differentiation step from $A_{s}$ to $A_{1}$. It is predominantly expressed in germ cells of testis and also expressed in Leydig cells (Oatley and Brinster, 2008).

The presence of functional c-kit receptor has been implicated in spermatogonial proliferation, survival and adhesion to Sertoli cells. (Robinson et al., 2001) showed the expression of c-kit by pachytene spermatocytes and proposed that kit and kit ligand are essential for meiosis. ${ }_{6}$ and ${ }_{1}$ integrins present on the spermatogonial stem cells is enriched in the basal layer and may help to attach spermatogonial stem cells to laminin in the basement membrane (Shinohara et al., 1999). Consistent with this idea, transplant assays show that crude cell population can be enriched for germ-line stem cells by binding to laminin (the target of ${ }_{6}$ and ${ }_{1}$ integrins) but not to collagen or fibronectin (Spradling et al., 2001). Bone morphogenetic protein (BMP)-4 produced by extra embryonic ectoderm stimulates the growth and development of early germ cells. Sertoli cells produce another glial cell line derived neurotrophic factor (GDNF) that affects proliferation of pre-meiotic germ line cells including stem cells (Beumer et al., 2000). The GDNF contributes to paracrine regulation of spermatogonial self-renewal and differentiation (Meng et al., 2000). The RNA helicase vasa are also expressed in developing germ cells of many species. In the absence of vasa, male germ cell proliferation is reduced severely in spermatogonial stages (Spradling et al., 2001).

Dazl (deleted in azoospermia-like) RNA binding protein, cyclin D2 and retinoic acid (RA) are among the other factors that regulate spermatogenesis (Almstrup et al., 2005). RA and retinoid X receptor are involved in differentiation of spermatogonia. SCF-ckit system is involved in $A_{1}$ spermatogonial differentiation (De Rooij, 2001). Genetic studies indicate that the bcl-2 family plays a key role in integrating the positive and negative signals on spermatogonial survival with certain members promoting cell survival (viz. Bcl-2, Bcl-xl, Bcl-w and A1/Bfl-1) and others promoting cell death (viz. Bax, Bak, Bad and Bim) (Adams and Cory, 1998). Transgenic loss of the Sertoli cell produced glial cell line derived neurotrophic factor (GDNF) function results in depletion of stem cell reserves, whereas in mice over expressed GDNF accumulate undifferentiated interactions between hormones and cytokines is most likely required to establish and sustain optimal spermatogonial development (McIntyre et al., 2008). 


\section{A New Ray of Hope to Augment Fertility with Spermatogonial Stem Cells}

SSC could herald a new era in medical science if we could apply it for gene therapy and controlling reproduction failure in males, both in human medicine and animal sciences. The spermatogonial stem cells (SSC) are the only adult stem cells that donate genetic material to the progeny. Researchers are harnessing to utilize the harvested SSC to culture and thereafter transplanting them into the recipient animals, with an aim to boost the sperm production of prized bulls. The technology would help to produce semen from exotic bulls having considerably higher genetic worth from indigenous scrub bull. In veterinary practice, many prized bulls often fail to reproduce due to certain andrological problems like poor libido or compromised spermatogenesis. Valuable germplasm of such males may be produced and utilized for artificial insemination by SSC culture and in vitro maturation of sperm cells. Moreover, the time lapsed during estimating the sire summary could be drastically reduced by implementing the SSC transplantation into pubescent males. Another broader area of stem cell research is production of transgenic animals by nuclear transfer of adult stem cells (Saito et al., 2008). Basic research in this area would help to understand the cascade of molecular biological pathways involved in spermatogenesis and also could lead to discovery of path breaking therapeutics for infertility and/ or subfertility (Marques-Mari et al. 2009, Du and Taylor, 2009). Further, SSC have several applications in ex-situ conservation of endangered species.

\section{Conclusion}

Spectacular new findings on pluripotent cells and their capacity to transform and differentiate into various cell-types of the germ line offer path breaking opportunities for germ line conservation and manipulation. The cascade of molecular events that virtually results in spermatogenesis from a group of spermatogonial stem cells is not yet fully understood. Few molecules such as GDNF, SCF-C-kit system, cyclin D2, Dazl protein, RA, Bcl-2 family have been identified to play a role in regulation of spermatogonial stem cell differentiation and apoptosis. Although studies with these molecules provide clues to the understanding of spermatogonial stem cell behavior in its niche, development of advanced culture systems should lead to complete understanding of spermatogenesis.

Whether these factors affect spermatogonia directly or are intermediates in the gonadotrophins response remains unclear. Several pertinent queries await valid explanations on the process of SSC differentiation and self-renewal. At present the primary challenges are to develop methods for obtaining pure populations of stem cells, for integrating stable exogenous DNA into these populations. The stem cell research is virtually in its infancy. A number of queries are yet to be answered, like, identification of constituents of media to culture the stem cells that they could be maintained in the uncommitted state. The pathways regulating pluripotency vis-à-vis the required growth factor vary considerably with species. For example, human and mouse ESC merely require LIF but bFGF. To the contrary, LIF which is required for LIFISTAT pathway is indispensable for culturing murine and bovine ESC. In conclusion, despite a lot of controversies over the hype and hope of stem cell research, it can be expected that the field holds great promise in treating many diseases that were virtually thought impossible once upon a time.

\section{References}

1. Abel, M. H., Baker, P. J., Charlton, H. M., Monteiro, A. Verhoeven, G., De Gendt, K., Guillou, F. and O'Shaughnessy, P. J. (2008). Spermatogenesis and Sertoli cell activity in mice lacking Sertoli cell receptors for folliclestimulating hormone and androgen. Endocrinol., 149(7): 3279-3285.

2. Adams, J. M. and Cory, S. (1998). The Bcl-2 family: arbiters of cell survival. Science, 281: 1322-1326.

3. Albanesi, C., Geremia, R., Giorgio, M., Dolci, S., Sette, C. and Rossi, P. (1996). A cell- and developmental stagespecific promoter drives the expression of a truncated c-kit protein during mouse spermatid elongation. Development, 122: 1291-1302.

4. Almstrup, K., Hoei-Hansen, C. E., Nielsen, J. E., Wirkner, U., Ansorge, W., Skakkebaek, N. E., Rajpert-De, M. E. and Leffers, H. (2005). Genome-wide gene expression profiling of testicular carcinoma in situ progression into overt tumours. The British J. Cancer., 92: 1934-1941.

5. Amann, R.P. (2008). The Cycle of the Seminiferous Epithelium in Humans: A Need to Revisit? J. Androl., 29(5): 469-487.

6. Beumer, T. L., Roepers-Gajadien, H. L., Gademan, I. S., Kal, H. B. and de Rooij, D. G. (2000). Involvement of the D-type cyclins in germ cell proliferation and differentiation in the mouse. Biol. Reprod., 63: 1893-1898.

7. Brinster, R. L. and Avarbock, M. R. (1994). Germ-line transmission of donor haplotype following spermatogonial transplantation. Proc. Natl. Acad. Sci. USA., 91: 1130311307.

8. Clermont, Y. (1966a). Renewal of spermatogonia in man. Am. J. Anat., 118: 509-524.

9. Clermont, Y. (1966b). Spermatogenesis in man: a study of the spermatogonial population. Fertil. Steril., 17: 705-721.

10. Clermont, Y. and Bustos-Obregon, E. (1968). Reexamination of spermatogonial renewal in the rat by means of seminiferous tubules mounted 'in toto'. Am. J. Anat., 122: 237-347. 
237-347.

11. Clermont, Y. and Leblond, C. P. (1959). Differentiation and renewal of spermatogonia in the monkey, Macaca rhesus. Am. J. Anat., 104: 237-273.

12. Clermont, Y. and Trott, M. (1969). Duration of the cycle of the seminiferous epithelium in the mouse and hamster determined by means of $3 \mathrm{H}$-thymidine and radioautography. Fertil. Steril., 20: 805-817.

13. De Rooij, D. and Lok, D. (1987). Regulation of the density of spermatogonia in the seminiferous epithelium of the Chinese hamster: II. Differentiating spermatogonia. Anat Rec., 217: 131-136.

14. De Rooij, D. G. (1998). Stem cells in the testis. Int. J. Exp. Pathol., 79(2): 67-80.

15. De Rooij, D. G. (2001). Proliferation and differentiation of spermatogonial stem cells. Reprod., 121:347-354.

16. De Rooij, D. G. and Grootegoed, J. A. (1998). Spermatogonial stem cells. Curr. Opin. Cell. Biol., 10: 694701.

17. De Rooij, D. G. and Janssen, J. M. (1987). Regulation of the density of spermatogonia in the seminiferous epithelium of the Chinese hamster: I. Undifferentiated spermatogonia. Anat Rec., 217: 124-130.

18. De Rooij, D. G., Okabe, M. and Nishimune, Y. (1999). Arrest of spermatogonial differentiation in jsd/jsd, S117H/S117H, and cryptorchid mice. Biol. Reprod., 61: 842-847.

19. De Rooij, D. G., van Alphen, M. M. and van de Kant, H .J. G. (1986). Duration of the cycle of the seminiferous epithelium and its stages in the rhesus monkey (Macaca mulatta). Biol. Reprod., 35: 587-591.

20. De Rooij, D.G., van de Kant, H. J. G., Dol, R., Wagemaker, G., van Buul, P. P. W., van Duijn-Goedhart, A., de Jong, F. H. and Broerse, J. J. (2002). Long-term effects of irradiation before adulthood on reproductive function in the male rhesus monkey. Biol. Reprod., 66: 486-494.

21. Du, H. and Taylor, H. S. (2009). Stem cells and female reproduction. Reprod Sci., 16(2):126-139.

22. Evans, M. J. and Kaufmann, M.H. (1981). Establishment in culture of pluripotential cells from mouse embryos. Nature, 292: 154-156.

23. Franchi, L. L. and Mandl, A. M. (1964). The ultrastructure of germ cells in foetal and neonatal male rats. J. Embryol. Exp. Morph., 12: 289-308.

24. Ginsburg, M., Snow, M. H. and McLaren, A. (1990). Primordial germ cells in the mouse embryo during gastrulation. Dev., 110: 521-528.

25. Hersmusa, R., de Leeuwa, H. C. G. M. B., Katja, P., Wolffenbuttel, K. P., Drop, S. L. S., Oosterhuis, J. W., Cools, M. and Looijengaa, L. H. J. (2008). New insights into type II germ cell tumor pathogenesis based on studies of patients with various forms of disorders of sex development (DSD). Mol. Cell. Endocrinol., 291(1-2): 1-10.

26. http://www.allaboutpopularissues.org/pros-and-cons-ofstem-cell-research.htm: Pros And Cons Of Stem Cell Research.

27. Huckins, C. and Clermont, Y. (1968). Evolution of gonocytes in the rat testis during late embryonic and early post-natal life. Arch. Anat. Hist. Embryo., 51: 334-354.

28. Jaenisch, R. and Young, R., (2008). Stem cells, the molecular circuitry of pluripotency and nuclear reprogramming. Cell, 132: 567-582.

29. Lawson, K. A. and Pederson, R. A. (1992). Clonal analysis of cell fate during gastrulation and early neurulation in the mouse. In: CIBA foundation symposium, 165 New York, John Wileys and Sons, USA., pp. 3-26.
30. Lok, D., Weenk, D. and de Rooij, D. G. (1982) Morphology, proliferation and differentiation of undifferentiated spermatogonia in the Chinese hamster and the ram. Anatomical Record., 203(1): 83-99.

31. Marques-Mari, A. I., Lacham-Kaplan, O., Medrano, J. V., Pellicer, A. and Simón, C. (2009). Differentiation of germ cells and gametes from stem cells. Hum. Reprod. Update. 15(3): 379-390.

32. Marshall, G. R., Zorub, D. S. and Plant, T. M. (1995). Follicle-stimulating hormone amplifies the population of differentiated spermatogonia in the hypophysectomized testosterone-replaced adult rhesus monkey (Macaca mulatta). Endocrinol., 136: 3504-3511.

33. Matsui, Y., Zsebo, K. and Hogan, B. L. M. (1992) Derivation of pluripotential embryonic stem cells from murine primordial germ cells in culture. Cell, 70: 841-847.

34. McIntyre, A., Gilbert, D., Goddard, N., Looijenga, L. and Shipley, J. (2008). Genes, chromosomes and the development of testicular germ cell tumors of adolescents and adults, Genes, Chrom. Cancer, 47(7): 547-557.

35. Meng, X., Lindahl, M., Hyvönen, M. E. Parvinen, M., de Rooi,j D. G., Hess, M. W., Raatikainen-Ahokas, A., Sainio, K., Rauvala, H., Lakso, M., Pichel, J. G., Westphal, H., Saarma, M. and Sariola, H. (2000). Regulation of cell fate decision of undifferentiated spermatogonia by GDNF. Science, 287: 1489-1493.

36. Oatley, J. M. and Brinster, R. L. (2008). Regulation of spermatogonial stem cell self-renewal in mammals. Annual Rev. Cell Dev. Biol., 24: 263-286.

37. Ogawa, T. (2008). Reproductive stem cell research and its application to urology. Int. J. Urol., 15(2): 121-127.

38. Ramaswamy, S., Marshall, G. R., McNeilly, A. S. and Plant, T. M. (2000). Dynamics of the follicle-stimulating hormone (FSH)-inhibin B feedback loop and its role in regulating spermatogenesis in the adult male rhesus monkey (Macaca mulatta) as revealed by unilateral orchidectomy. Endocrinol., 141: 18-27.

39. Robinson, L. L., Gaskell, T. L., Saunders, P. T. K. and Anderson, R. A. (2001). Germ cell specific expression of ckit in the human fetal gonad. Mol. Human Reprod., 7: 845852.

40. Rossant, J. (2008). Stem cells and early lineage development. Cell, 132: 527-531.

41. Russell, L. D., Ettlin, R. A., Sinha-Hikkim, A. P., and Clegg, E. D. (1990). Mammalian spermatogenesis. In Histological and Histopathological Evaluation of the testis (Eds Russell, L. D., Ettlin, R. A., Sinhahikim, A. P. and Clegg, E. D. D.), Cache River Press, Clearwater, USA., pp. 1-40.

42. Saito, S., Sawai, K., Murayama, Y., Fukuda, K. and Yokoyama, K. (2008). Nuclear transfer to study the nuclear reprogramming of human stem cells. Methods Mol. Biol. 438: 151-169.

43. Shinohara, T., Avarbock, M. R. and Brinster, R. L. (1999). $\beta 1$ and $\alpha 6$-integrin are surface markers on mouse spermatogonial stem cells. Proc. Natl .Acad. Sci. USA., 96: 5504-5509.

44. Simorangkir, D. R., Marshall, G. R., Ehmcke, J., Plant, T. M. and Schlatt, S. (2005). Pre-pubertal expansion of dark and pale type A spermatogonia in the rhesus monkey (Macaca mulatta) results from proliferation during infantile and juvenile development in a relatively gonadotropin independent manner. Biol. Reprod., 73: 1109-1115.

45. Spradling, A., Drummond-Barbosa, D. and Kai, T. (2001). Stem cells find their niche. Nature, 414:98-104

46. Tam, P. and Snow, M. H. L. (1981). Proliferation and 
migration of primordial germ cells during compensatory growth in mouse embryos. J. Embryol. Exp. Morph., 64: 133-147.

47. Tegelenbosch, R. A. J. and de Rooij, D. G. (1993). A quantitative study of spermatogonial multiplication and stem cell renewal in the $\mathrm{C} 3 \mathrm{H} / 101 \mathrm{~F} 1$ hybrid mouse. Mut. Res., 290: 193-200.

48. Van Alphen, M. M. and de Rooij, D. G. (1986). Depletion of the seminiferous epithelium of the rhesus monkey, Macaca mulatta, after X-irradiation. Br. J. Cancer (Suppl)., 7:102-104.

49. Van Pelt, A. M. M., Roepers-Gajadien, H. L., Gademan, I. S.,
Creemers, L. B., de Rooij, D. G. and van Dissel-Emiliani, F. M. F. (2002). Establishment of cell lines with rat spermatogonial stem cell characteristics. Endocrinol., 143:845-1850.

50. Vergouwen, R. P., et.al.(1991). Proliferative activity of gonocytes, Sertoli cells and interstitial cells during testicular development in mice. J. Reprod. Fertil., 93: 233-243.

51. Yasuzumi, G., Tanaka, H. and Tezuka, O. (1960). Spermatogenesis in animals as revealed by electron microscopy VIII. Relation between the nutritive cells and the developing spermatids in a pond snail, Cipangopaludina malleata Reeve. The J. Cell Biol., 7(3): 499-504. 